\title{
Occipital Aneurysmal Bone Cysts in an Adult Patient: A Rare Case and Review of Literature
}

Oktay GÜRCAN ${ }^{1}$, Atilla KAZANCI ${ }^{1}$, Ahmet G. GÜRÇAY ${ }^{1}$, Halil C. KÜÇÜKYILDIZ ${ }^{1}$, İsmail BOZKURT ${ }^{1}$, Ömer F. TÜRKOĞLU ${ }^{1}$, Murad BAVBEK ${ }^{1}$

${ }^{1}$ Department of Neurosurgery, Ankara Ataturk Education and Research Hospital, Ankara, Turkiye.

\section{ABSTRACT}

This study aimed to report a rare case of occipital aneurysmal bone cysts (ABCS) in an adult patient. ABCs account for $1 \%$ of primary bone tumors. They are usually seen in pediatric age and rare in adults. They are benign fibro-osseous lesions, but they also tend to double in size rapidly and destruct the morphology of the bone. They have a tendency to extend to the long bones and vertebral column. The calvarial ABCS are 3\%-6\% of ABC. They usually affect the frontal and temporal bones of the skull, and cranial nerve findings are frequently seen. In the adulthood, occipital ABCs are extremely rare. Sixteen cases of occipital ABC, average age 15 years, have been reported in the literature. A 50-year-old female patient was admitted to the clinic with the history of an occipital mass lesion, which had been growing for 6 months. Magnetic resonance imaging and computed tomography of the cranium revealed an irregular-shaped destructive lesion of $55 \times 18 \times$ $28 \mathrm{~mm}^{3}$ in the diploe part of the occipital bone. The mass with an approximately $6 \mathrm{~cm}$ radius, and $1 \mathrm{~cm}$ normal bone edge was completely excised. Because of total resection, no adjuvant therapy was performed. Neither recurrence nor residual lesion was observed in the postoperative 24 months.

Key words: Adult, aneurysmal bone cyst, occipital

\section{INTRODUCTION}

Aneurysmal bone cysts (ABCS), first described in 1942 by Jaffe and Lichtenstein, are uncommon, benign, rapidly growing osteolytic lesions consisting of two segments: an intraosseus, destructive tumor and an extraosseus, aneurysm-like cyst of the bone, which make up for 1\%-2\% of all primary osseous tumors (1). The true etiology and pathophysiology are not clear. It is believed that $A B C$ s are a result of a vascular malformation that mostly affects the metaphysis of the long bones. They are benign fibro-osseous lesions but they also tend to double in size rapidly and destruct the morphology of the bone. They have a tendency to extend to the long bones and vertebral column (2-7). They are usually seen in pediatric age and rare in adults. Only 3\%-6\% of all ABCs present with extra- or intracranial extension found in the skull. They usually affect the frontal and temporal bones of the skull, and cranial nerve findings are frequently seen. In the adulthood, occipital ABC is extremely rare. This study reported a rare case of occipital $A B C$ in an adult patient with clinical and radiological features and treatment strategy.

\section{CASE REPORT}

A 50-year-old female patient was admitted to the clinic with the history of an occipital mass lesion, which had been growing for 6 months. Magnetic resonance imaging and computed tomography (CT) of the cranium revealed an irregularshaped destructive lesion of $55 \times 18 \times 28 \mathrm{~mm}^{3}$ in the diploe part of the occipital bone (Figs. 1 and 2). The mass with an approximately $6 \mathrm{~cm}$ radius, and $1 \mathrm{~cm}$ normal bone edge was completely excised, and cranioplasty with a titanium mesh was performed (Fig. 3). Immunohistochemical studies (SMA: Smooth Muscle Actin, EMA: Epithelial Membrane Antigen, CD34, ALK: Anaplastic Lymphoma Kinase, (D117, pancytokeratin, vimentin, desmin, and S100) revealed an ABC. Because 


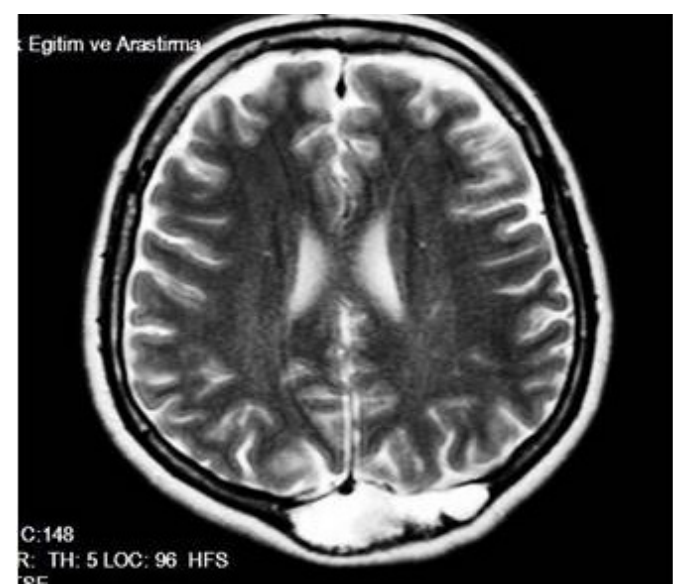

FIGURE 1: Axial MRI revealing a destructive lesion in the occipital bone.

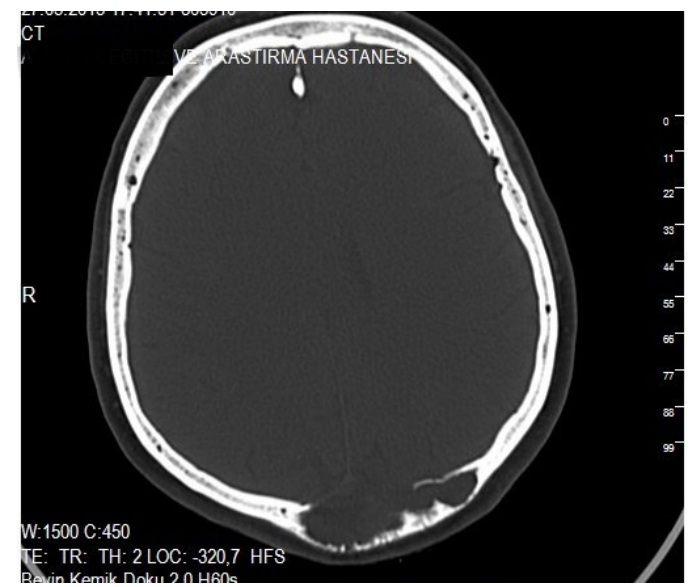

FIGURE 2: CT scan showing the occipital bone with a locally destructive mass.

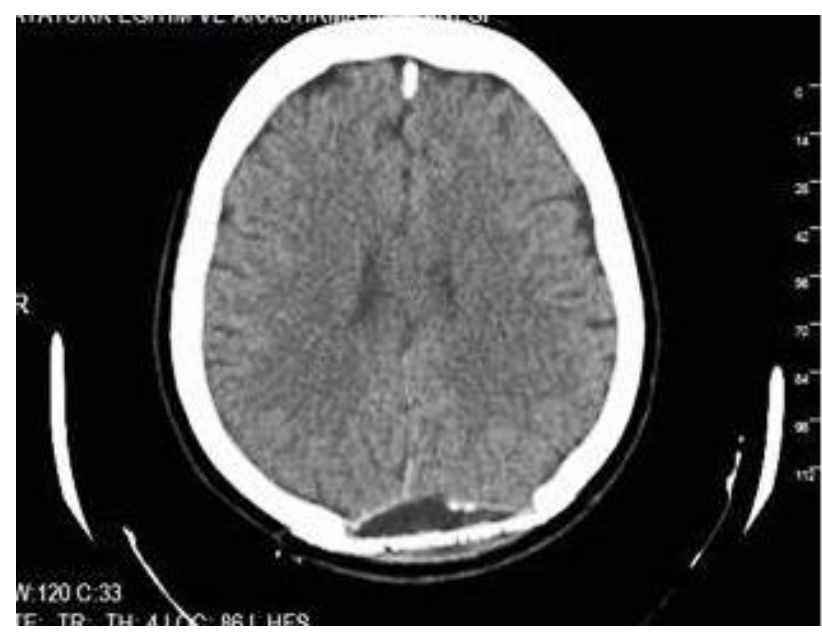

FIGURE 3: Postoperative CT scan showing total resection of the lesion and cranioplasty with a titanium mesh.

of total resection, no adjuvant therapy was performed. Neither recurrence nor residual lesion was observed in the postoperative 24 months.

\section{DISCUSSION}

Accounting for $1 \%-2 \%$ of all osseous tumors, $A B C$ are rare and benign lesions, but they tend to behave destructively locally. Their characteristic blown-out appearance arises from a bloodfilled fibrous tumor-like cyst that expands the surrounding bone. They are most commonly found in the vertebrae and metaphysis of the long bones. $(2,3,6,8-10)$. Only a small percentage of $A B C s$ are found in the skull and mandible, ranging from 3 to $6 \%$. They are mostly diagnosed during an inspection where a scalp mass is observed but may also present as an intracranial mass or cerebral hemorrhage. Most $A B C$ s that are found in the skull tend to lie in the temporal bone and very rarely in the occipital bone $(6,10$ 12). Only eight cases of adult occipital ABCs have been reported in the literature till date; the present case is the ninth case (Table 1). Although the specific pathogenesis of $A B C$ is unexplained, the most commonly accepted concept is the formation of aneurysmal cysts following benign or malignant lesions. However, only one-third of the cases have an identifiable initial lesion. Giant cell tumor (19\%-39\%) is the leading precursor followed by osteoblastoma, angioma, and chondroblastoma. Fibrous dysplasia, unicameral bone cyst, nonossifying fibroma, chondromyxoid fibroma, fibrous histiocytoma, eosinophilic granuloma, and osteosarcoma are the least common causes $(6,11)$. In 1942, ABCs were defined by Jaffe and Lichtenstein 
TABLE 1: Summary of cases of adult occipital aneurysmal bone cysts reported in the English literature

\begin{tabular}{|c|c|c|c|c|c|}
\hline Age/Sex & Location & Pathology & Clinical Presentation & Author & Year \\
\hline 19/Female & Occipital & Aneurysmal bone cysts & Headache and palpable mass & Luccarelli et al. & 1980 \\
\hline 18/Male & Occipital & Aneurysmal bone cysts & Palpable mass & Bilge et al. & 1983 \\
\hline 21/Male & Occipital & Aneurysmal bone cysts & Focal tenderness & David et al. & 1993 \\
\hline 19/Male & Occipital & $\begin{array}{l}\text { Aneurysmal bone cysts + } \\
\text { Fibrous dysplasia }\end{array}$ & Focal tenderness & Itshayek et al. & 2002 \\
\hline 35/Male & Temporal + Occipital & $\begin{array}{l}\text { Aneurysmal bone cysts + } \\
\text { Fibrous dysplasia }\end{array}$ & Headache & Iseri et al. & 2005 \\
\hline 19/Female & Parietal + Occipital & $\begin{array}{l}\text { Aneurysmal bone cysts + } \\
\text { Fibrous dysplasia }\end{array}$ & Headache & Mattei et al. & 2005 \\
\hline 54/Female & Occipital & Aneurysmal bone cysts & Focal tenderness & Lin et al. & 2007 \\
\hline 20/Male & Occipital & $\begin{array}{l}\text { Aneurysmal bone cysts + } \\
\text { Osteoblastoma }\end{array}$ & Headache & Han et al. & 2008 \\
\hline 50/Female & Occipital & Aneurysmal bone cysts & Palpable mass & Present case & \\
\hline
\end{tabular}

as lesions with distinct radiological finding of distended and ballooned-out periosteum (1). Although benign, ABCs are locally destructive causing elevation of the periosteum above and eroding the cortical bone to a very thin border, resulting in the typical "blown-out" or" soap bubble" appearance. In the vault bone, the lesion originates within the diploic space expanding the distance between the inner and outer tables of the cranium. CT and MRI are useful in establishing the diagnosis where multiloculation of the cyst demonstrates the characteristic fluid levels within the cyst. These levels are caused by partly cystic and partly solid content of the lesion where the solid part is clearly visible with contrast enhancement. Due to the breakdown of blood contents within the cyst, septa are formed and a heterogenous lesion can be observed in the MRI, which would also confirm the multiple fluid levels. Histological examination usually reveals cysts lined with spindle-shaped fibroblasts surrounding the venous bloodfilled lesion. Multinucleated giant cells along with stromal cells may also be scattered within the lesion $(6,8,9,13,14)$.

Treatment modalities range from simple surgery to a combination of methods. Although curettage followed by bone grafting is the most commonly employed modality, it has a high recurrence rate of $20 \%-40 \%(7,11,15,16)$. In the present case, the cyst was completely and aggressively scraped out to decrease the chance of recurrence. The remaining cavity was filled with donor bone tissue (allograft), bone chips (autograft), or other materials $(2,3,6,7,8)$.

A marginal or wide excision of the surrounding bone is the suggested surgical modality to decrease the chances of recurrence. If the lesion is found in an expandable bone such as the rib or fibula, aggressive wide excision is recommended $(6,12,13,17)$. In the present case, an extensive excision of the mass with 1-cm normal bone edge was performed. Adjuvant therapy such as cryotherapy may be employed to decrease the chances of recurrence. If other modes of treatment prove inefficient, adjuvant radiotherapy following aggressive excision may also be performed.

\section{CONCLUSION}

Adult occipital $A B C$ s are extremely rare tumors. It is believed that total resection with a 1-cm normal bone margin of $A B C$ does not need any adjuvant therapy. Routine controls must be done, and adjuvant therapies should be advised for the partially resected and recurrent lesions.

\section{REFERENCES}

1. Jaffe $H$, Lichtenstein L: Solitary unicameral bone cyst: with emphasis on the roentgen picture, the pathologic appearance, and the pathogenesis. Arch Surg.1942;44:10041025.

2. Ameli NO, Abbassioun K, Azod A, Saleh H: Aneurysmal bone cyst of the skull. Can J Neurol Sci. 1984; 11:466-471.

3. Cakirer S, Cakirer D, Kabukcuoglu F: Aneurysmal bone cyst of the orbit: A case of rare location and review of the literature. Clin Imaging.2002; 26:386-91.

4. Bilge T, Coban O, Ozden B, Turantan I, Türker K, Bahar S: Aneurysmal bone cysts of the occipital bone. Surg Neurol. 1983; Sep;20(3):227-30. 
5. Dávid K, Horváth Z, Horváth A, Illés T: Aneurysmal bone cyst of the occipital bone: case report. Surg Neurol. 1993;Oct;40(4):332-5.

6. Genizi J, Srugo I, Attias D, Ben-Sira L, Braun J, Bamberger ES, Margalit N, Constantini S: Giant pediatric aneurysmal bone cysts of the occipital bone: case report and review of the literature. Pediatr Neurol.2011; Jul;45(1):42-4.

7. Keuskamp PA, Horoupian DS, Fein JM: Aneurysmal bone cyst of the temporal bone presenting as a spontaneous intracerebral hemorrhage: case report. Neurosurgery. 1980;7:166-70.

8. Cataltepe $\mathrm{O}$, Inci $\mathrm{S}$, Ozcan OE, Saglam S, Erbengi A: Aneurysmal bone cyst of the frontal bone. Surg Neurol.1990; 33:391-4.

9. Lin SP, Fang YC, Chu DC, Chang YC, Hsu CI: Characteristics of cranial aneurysmal bone cyst on computed tomography and magnetic resonance imaging. J Formos Med Assoc.2007; Mar;106(3):255-9.

10. Perrotti V, Rubini C, Fioroni M, Piattelli A: Solid aneurysmal bone cyst of the mandible. Int J Pediatr Otorhinolaryngol.2004; Oct;68(10):1339-44.

11. Itshayek E, Spector S, Gomori M, Segal R: Fibrous dysplasia in combination with aneurysmal bone cyst of the occipital bone and the clivus: case report and review of the literature.
Neurosurgery.2002; Sep;51(3):815-7; Review. discussion 817-8.

12. Segall L, Cohen-Kerem R, Ngan BY, Forte V: Aneurysmal bone cysts of the head and neck in pediatric patients: a case series.. Int J Pediatr Otorhinolaryngol.2008; Jul;72(7):977-83.

13. Purohit A, Chopra S, Sinha VD, Dhanker SR: Aneurysmal bone cyst of the temporal bone: case report. Neurology India.2002; 50; 511-513.

14. Mattei TA, Mattei JA, Ramina R, Aguiar PH: Fibrous dysplasia in combination with aneurysmal bone cyst presenting as a subarachnoid haemorrhage. Neurol Sci. 2005;Jul;26(3):17881.

15. Han X, Dong Y, Sun K, Lu Y: A huge occipital osteoblastoma accompanied with aneurysmal bone cyst in the posterior cranial fossa. Clin Neurol Neurosurg. 2008;Mar;110(3):282-5.

16. Luccarelli G, Fornari M, Savoiardo M: Angiography and computerized tomography in the diagnosis of aneurysmal bone cyst of the skull: case report. J Neurosurg.1980; Jul; 53(1):113-6.

17. Iseri PK, Efendi $H$, Demirci $A$, Komsuoglu S: Fibrous dysplasia of the cranial bones: a case report and review of the literature. Yale J Biol Med.2005; May;78(3):141-5. 